\title{
Scalar characteristics of a lean premixed turbulent V-shape flame (air-butane)
}

\author{
M. S. Boulahlib, S. Boukebbab, I. Amara \& E. Ferkous \\ Department of Mechanical Engineering, \\ Constantine University, Algeria
}

\begin{abstract}
This paper proposes an experimental study of the scalar fields of a lean V shape premixed turbulent flame. The thermometry with the thermocouple numerically compensated was used for determining the thermal fields of a premixed butaneair V shape flame. The structure of both the inert and reactive jet was studied for a Reynolds number of 7000 . Turbulence is generated by a perforated grid situated upstream. The main results of the thermal field in the $\mathrm{V}$ shape flame have showed more important results and a representative form of the inner structure of the flame was then obtained. The study is to determine how the turbulence and equivalence ratio can affect the temperature field, the flame height, the variable progress and therefore the combustion process.
\end{abstract}

Keywords: experimental, thermocouple, compensated temperature, premixed combustion, butane, turbulence grid.

\section{Introduction}

Knowledge of the flame structure can be improved by a better comprehension of the flow turbulence phenomena and combustion. So, it is necessary to understand the physical and chemical processes dominating within the combustion system. In most practical applications, premixed turbulent combustion takes place in the laminar flamelet regime. This combustion regime is characterized by the combustion mode in which all length scales of the turbulent structures in the reacting flow are larger than the flame thickness.

In the flamelet regime, where one assumes a chemical reaction time lower than the turbulence time scale, the effects of the interaction between the phenomena of turbulence and combustion are represented at the same time by the 
local and global structure of the flame. The flame is folded by the turbulent flow, which leads to an increase in its surface. Simultaneously, the local structure of the flame is modified by the flame front orientation and shearing of the turbulent flow represented by the flow divergence in the tangent plan flame. Poinsot et al. [12], based on numerical results obtained from DNS, estimate in the flamelet regime that the small structures are able to penetrate and modify the internal structure of the flame front. Peters [11], supposes that the small structures can penetrate the preheating zone, but that they are unable to disturb the fine reaction zone inside the flame front. The preliminary steps of measuring the dynamic and scalar structure using a $\mathrm{V}$ shape flame have been performed by a number of researchers. Cheng et al. [4] investigated the conditional velocity statistics in premixed $\mathrm{CH}_{4}$-air and $\mathrm{C}_{2} \mathrm{H}_{4}$-air turbulent flames. Miles and Gouldin [7] developed and applied an experimental technique for determining the mean rate of chemical reaction $\langle\mathrm{w}>$, in turbulent $\mathrm{V}$-shape flames. The influence of free stream on the statistics of a turbulent premixed $\mathrm{V}$-flame is numerically investigated by Chan et al. [3] and is compared to experimental results. Knaus et al. [5], in an article using a new technique for obtaining instantaneous, high resolution, three dimensional thermal structure data from turbulent flames, crossed-plane Rayleigh imaging. This technique is used to measure temperature gradient data for a lean, premixed methane-air turbulent V-flame. Recently Tang and Chan [15], using a contour advection numerical model, have investigated the effect of turbulence on various quantities such as flame brush thickness and flame surface density.

One of the objectives of this paper concerns the characterization of flame structure for a premix in terms of the flame height, temperature field and mean progress variable. The simultaneous effect of several scales of turbulent flow on the flame front was studied. Stationary flames were recorded and treated to describe the space properties for various turbulence conditions and equivalence ratios. This quantity is estimated in order to characterize the average interaction between the flame scalar field and dynamic one in which it is propagated.

\section{Experimental device}

The experimental device used consists of a turbulent burner where the premixing to butane/air is convected with a mean velocity of $6 \mathrm{~m} / \mathrm{s}$ (Boulahlib et al. [1]). The burner includes a feeding system of butane, which is injected axially into a premixer with air. A laminarisation system, and a set of grids perfectly dimensioned according to the expected turbulence, allows the control of the turbulence level. Spaces between the holes give rise to wakes that mix downstream from the grid. In the absence of a turbulence grid, the outgoing flow of the burner is on the level of very weak turbulence (lower than $1 \%$ ). The burner exit section has a length of $180 \mathrm{~mm}$ and a width of $6 \mathrm{~mm}$.

The grid turbulence is well-known and it is the only one that is connected with a homogeneous and isotropic turbulence. Interchangeable grid turbulence can generate various conditions of homogeneous and isotropic turbulence: laminar case and turbulence intensity is $6 \%, 6.4 \%$ and $7.5 \%$. Thus, the flames 


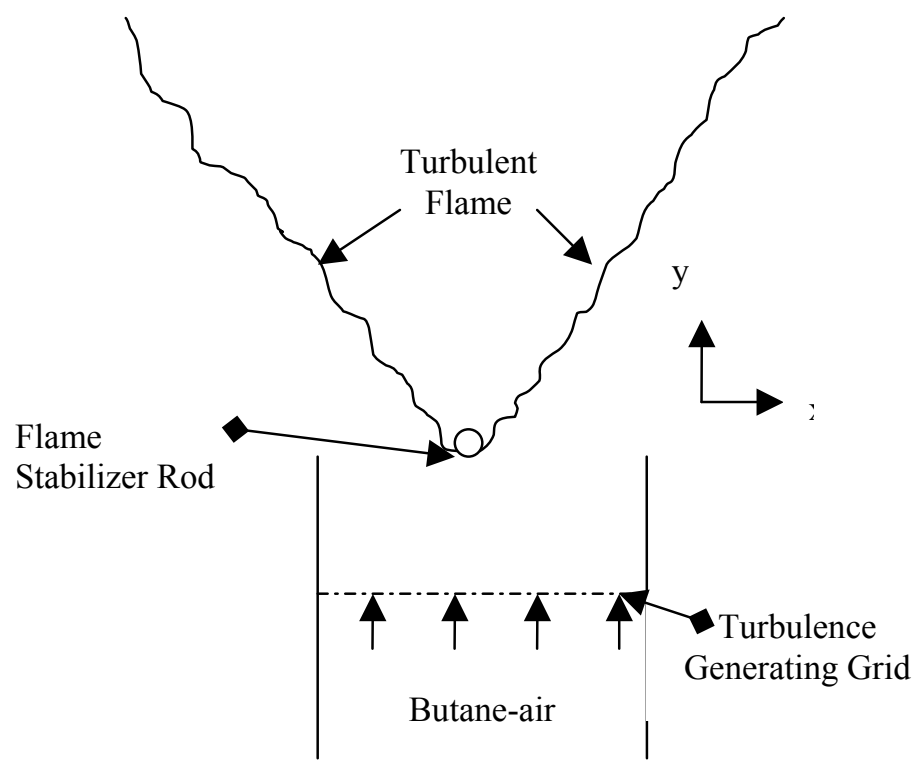

Figure 1: $\quad \mathrm{V}$-anchorage flame geometry.

produced with various conditions of equivalence ratio (equivalence ratio $=0.9 \div$ 1.4) and turbulence is propagated in the combustion chamber under atmospheric pressure (Figure 1). The characteristics of the turbulent flow like velocities were determined by Hot Wire. Table1 summarizes the turbulence characteristics and combustion parameters for the various flames displayed. The ratio $\mathrm{u}^{\prime} / \mathrm{S}_{\mathrm{L}}$, where $\mathrm{S}_{\mathrm{L}}$ represents the speed of non-stretched laminar flame (figure 3), allows one to combine the turbulence and combustion conditions. The values of $\mathrm{u}^{\prime} / \mathrm{S}_{\mathrm{L}}$ vary from 2.46 to 4.04 . The studied flames are located in the flamelet regime.

Table 1: $\quad$ Turbulence conditions.

\begin{tabular}{|l|l|l|l|l|l|l|l|c|}
\hline Grid & $\mathrm{M}(\mathrm{mm})$ & $\mathrm{d}(\mathrm{mm})$ & $\mathrm{d} / \mathrm{M}$ & $\sigma(\%)$ & $\begin{array}{l}\mathrm{C}_{\mathrm{D}} \\
(\%)\end{array}$ & $\mathrm{U}(\mathrm{m} / \mathrm{s})$ & $\mathrm{u}^{\prime}(\mathrm{m} / \mathrm{s})$ & $\begin{array}{l}\mathrm{u}^{\prime} / \mathrm{U} \\
(\%)\end{array}$ \\
\hline $\mathrm{P}$ & 2.40 & 2 & 0.83 & 0.38 & 37.5 & 5.75 & 0.425 & 7.4 \\
\hline $\mathrm{M}$ & 3.52 & 3 & 0.85 & 0.34 & 26.5 & 5.68 & 0.370 & 6.5 \\
\hline $\mathrm{G}$ & 4.54 & 4 & 0.88 & 0.30 & 18.4 & 5.28 & 0.318 & 6.0 \\
\hline
\end{tabular}

\subsection{Temperature measurement by thermocouples in a reacting flow}

A thermocouple is made of two wires of different types whose ends are connected by joints. When one of the junctions is maintained at a temperature different from the others, there appears in the electrical system an electromotive force due to the different nature of metals (the Seebeck effect). This electromotive force is a function of the temperature difference between the two junctions. In our study we use thermocouple type K. The hot weld of these 
thermocouples is made with two wires having small-diameters so as to increase the temporal and spatial resolutions of the measurement. The wires are fixed on pins that are more resistant to flow. Each pin is made of the same alloy as the corresponding part of the wire. The use of thermocouples for a temporal resolution of the measurement of high temperatures requires specific treatment of these values. When the temperature of the environment is high, the loss of radiant heat from the wires becomes important. Thus, the temperature measured by the hot junction is less than the temperature of the environment. These losses have been estimated and discussed by many authors (Scadron and Warshawsky [14], Bradly and Matthews [2], Paranthoën and Lecordier [10]). Their estimates by one of the proposed models can correct the difference between the thermocouple temperature and the actual temperature of the gas. In addition, the temporal resolution of the thermocouple signal is a very important parameter for studies of fluctuating flows. The thermocouple has been used in numerous applications of combustion. Neveu et al. [8] have coupled the measurement of temperature $(2 \mathrm{kHz})$ and speed obtained simultaneously to correlate and examine the turbulent flow of a non-pre mixed methane/air burner. Poireault [13] studied a 'swirl' type burner, in order to understand the influence of the number of swirls on the stabilization of the flame. He characterized the areas of the threedimensional flow through the modality of the probability function of the temperature signal. Larass [6] studied the thermal and dynamic fields in a domestic model boiler.

\subsubsection{Heat exchange}

The theoretical study of heat transfer between a thermocouple and the environment was carried out by Scadron and Warshawsky [14]. The study takes into account signal compensation for the losses by radiation and quantifies the response time of the thermocouple. There are also other studies that discuss the theoretical approach of this method and show its advantages and its limit (Nina and Pita [9], Neveu et al. [8]). The energy balance performed on a unit length $\mathrm{dx}$ of the thermocouple in a flow is presented below (eqn (1)). It is valid for an ideal welding of the fine wire of the thermocouple. This is considered as a cylindrical body.

Accumulation $($ Acc $)=$ Convection $(A)+$ Conduction $(B)+$ radiation $(C)+$ Catalysis (D)

$\pi \mathrm{r}^{2} \mathrm{dx} \rho \mathrm{c}_{\mathrm{P}} \frac{\partial \mathrm{T}_{\mathrm{c}}}{\partial \mathrm{t}}=2 \mathrm{r} \pi \mathrm{dxh}\left(\mathrm{T}_{\mathrm{g}}-\mathrm{T}_{\mathrm{c}}\right)-\mathrm{r}^{2} \pi \mathrm{dx} \lambda_{\mathrm{f}} \frac{\partial^{2} \mathrm{~T}_{\mathrm{c}}}{\partial \mathrm{x}^{2}}+2 \mathrm{r} \pi \mathrm{dx} \varepsilon_{\mathrm{c}} \sigma\left[\varepsilon_{\mathrm{pa}} \mathrm{T}_{\mathrm{pa}}^{4}+\varepsilon_{\mathrm{g}} \mathrm{T}_{\mathrm{g}}^{4}-\mathrm{T}_{\mathrm{c}}^{4}\right]+2 \mathrm{r} \pi \mathrm{dx} \mathrm{Q}_{c a t}$
Acc
A
B
$\mathrm{C}$
$\mathrm{D}$

\subsubsection{Digital compensation}

We recall that compensation is needed for two reasons. The first relates to the temperature displayed by a thermocouple, which is not necessarily the gas temperature of the environment, as a result of losses by radiation from high temperature thermocouples. For the gas temperature, it is necessary to estimate 
and correct those losses. The second reason relates to the response time of the thermocouple, which is limited by the inertia of two wires.

$$
\begin{gathered}
\frac{\partial \mathrm{T}_{\mathrm{c}}}{\partial \mathrm{t}}=\frac{4 \mathrm{Nu} \lambda_{\mathrm{g}}}{\mathrm{d}^{2} \rho \mathrm{c}_{\mathrm{p}}}\left(\mathrm{T}_{\mathrm{g}}(\mathrm{t})-\mathrm{T}_{\mathrm{c}}(\mathrm{t})\right) \\
\text { Or: } \tau_{\mathrm{cv}}=\frac{\mathrm{d}^{2} \rho \mathrm{c}_{\mathrm{p}}}{4 \mathrm{Nu} \lambda_{\mathrm{g}}} \\
\mathrm{T}_{\mathrm{g}}=\mathrm{T}_{\mathrm{c}}+\tau_{\mathrm{cv}}\left(\frac{\partial \mathrm{T}_{\mathrm{c}}}{\partial \mathrm{t}}-\frac{\varepsilon_{\mathrm{c}} \varepsilon_{\mathrm{pa}}}{1-\left(1-\varepsilon_{\mathrm{c}}\right) \cdot\left(1-\varepsilon_{\mathrm{pa}}\right)} \cdot \frac{4 \sigma\left(\mathrm{T}_{\mathrm{c}}^{4}-\mathrm{T}_{\mathrm{pa}}^{4}\right)}{\mathrm{d} \rho \rho_{\mathrm{p}}}\right)
\end{gathered}
$$

The equation obtained allows us to have simultaneously offsetting losses by radiation and inertia (eqn (4)). It is mainly a function of temperature measured by the wire and the Nusselt number. It should be noted that the Nusselt number is a function of the Reynolds number and therefore depends on the temperature of the gas.

\section{Results}

\subsection{Flame heights}

One of the items considered desirable in a data base on turbulent flames is the measurement of some macroscopic variables such as flame height (or length). They constitute important major elements to define the global spatial properties of the turbulent flames. The height of the flame $\mathrm{H}$ is defined as the value where the value of temperature is at maximum. Analyses of images of spontaneous emission of flame showed a reduction of the combustion process with the increase in the turbulence intensity. Indeed it is accompanied by a decrease from the height of the flame and can affect the average field and unruly directly on the flame height and the combustion process (Figure 2).

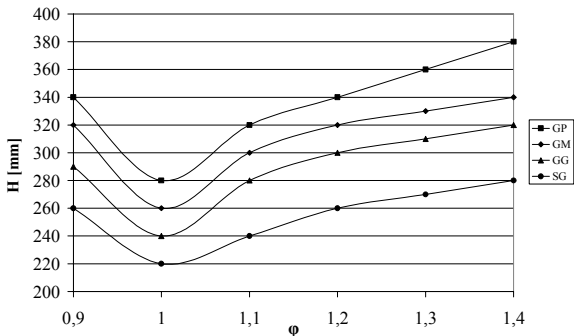

Figure 2: Flame heights with the equivalence ratio and turbulence.

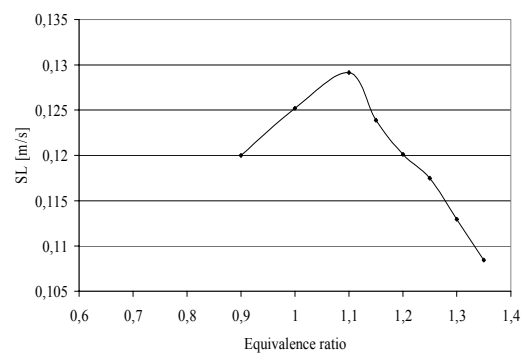

Figure 3: Laminar flame velocity. 
Regarding equivalence ratio, the increase from the lean burn, we can see that for various equivalence ratio worth of the flame height, all profiles vary in terms of sizes around the stoichiometry. In fact, $\mathrm{S}_{\mathrm{L}}$ decreases, with the equivalence ratio for $\varnothing<1$ (Fig3), and height flame increase significantly for the same mass flow. The flame heights allow us to highlight the existence of three areas. A first region of lean burn is characterized by large flame heights and low wrinkling, a second area corresponds to the location of the stoichiometric line with a significant reduction in the flame height and an increase in the wrinkling, and a final area of high equivalence ratio where there is a noteworthy increase in the size of the flames and decrease wrinkling. There is a discrepancy of these minimum sizes of the change in equivalence ratio inward depending on the increase in the turbulence intensity; this is explained by the interaction between combustion and turbulence.

\subsection{Laminar temperature flame}

Temperature profiles for laminar flames measured are shown in figures 4 and 5 , where temperature is plotted against a spatial coordinates $\mathrm{X}$. These data are measured using thermocouple and represent the average of 10 temperature fields. The evolution of the mean temperature profiles with different equivalence ratios and inlet velocities are carried out.

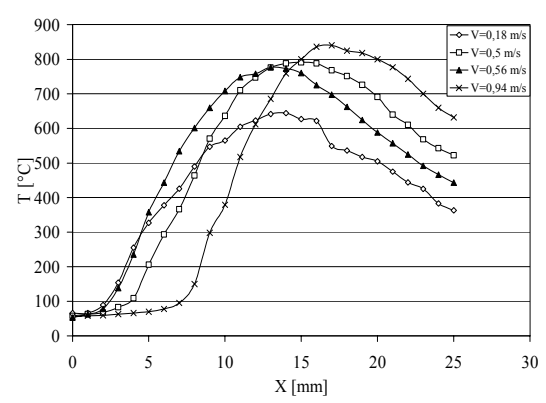

Figure 4: Effect of inlet velocity on temperature field.

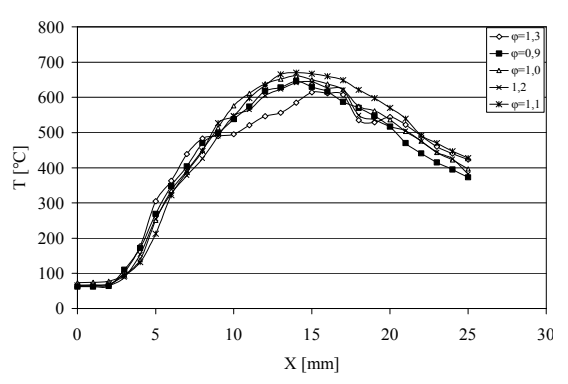

Figure 5: Temperature with equivalence ratio.

\subsection{Turbulent flame}

Figures 6-8 thus show the profiles of temperature in the laboratory coordinates as function of $y$ (various distances), $\varphi$ (equivalence ratio) and different grid (turbulence intensities). The trends of the variations of these quantities are as expected. The original temperature data are first fitted with a cubic spline, and then smoothly interpolated to yield equally spaced data. The experimental data on the temperature show a significant expansion of the gas away from the centerline in the radial direction because heat release. Temperature profiles measured in the same burner at different distances should be similar, and weakly affected by turbulence characteristics and mixture composition. The areas of maximum temperatures are situated on the 


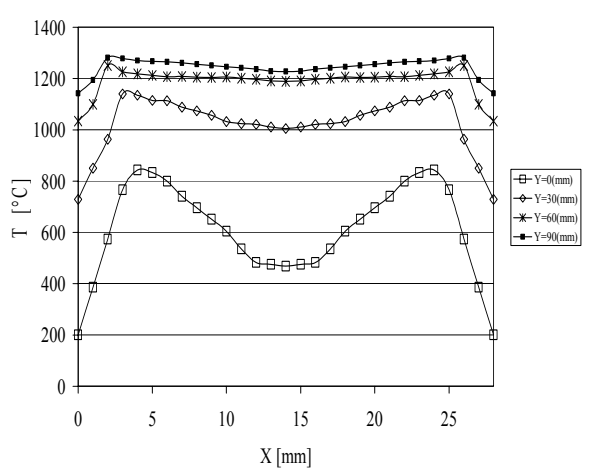

Figure 6: $\quad$ Flame temperature as a function of $\mathrm{y}$ for $\varphi$ $=0.9$ and $\mathrm{P}$ grid.

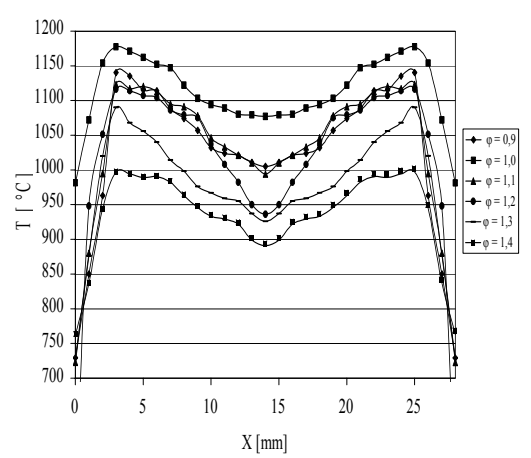

Figure 7: Mean temperature profile equivalence ratio at the burner exit.

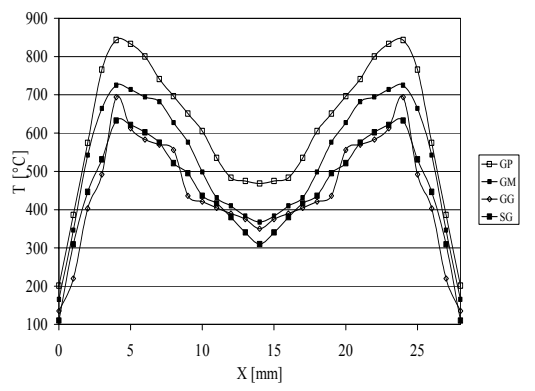

Figure 8: Temperature for various turbulence intensities at the burner exit plane.

banks of the flame (burned gas), and are at their lowest in the center (fresh gas). The fresh gas is kept at temperatures between 350 and $600^{\circ} \mathrm{C}$ for rich mixtures. This amount of heat gained by fresh gas is due to diffusion phenomena of free radicals and rich flames radiation. The minimum temperature at the outlet of the burner, then to grow quite quickly when one moves along the flame. The temperature is constant in the flame front from a certain height. Beyond this height the temperature remains relatively constant across the flame (only burn gas), on account of the turbulent kinetic energy that reaches its maximum value, just outside the jet, this is due mainly to the presence of a thermal gradient between the velocity jet of burned gas, and ambient air, which represents in terms of production the turbulent kinetic energy, the latter will suffer a decline throughout the flame, the influence of combustion is clear. We can note figure 6 that gradient are very close to those of upstream boundary of the luminous zone, with the spreading representing the uncertainties caused by flame flickering. The only slight deviation from the above observation is for the near $y=90 \mathrm{~mm}$, for which the final, peak 
temperature at the stagnation flame is upper than other case. Figure 8 shows the temperature profiles in the laboratory coordinates for the different equivalence ratio. Also indicated for reference are two important peak locations, which respectively correspond to the maximum temperature gradient, maximum heat release. It is of interest to note that while the deep violet radiation associated is with the luminosity, if lean hydrocarbon-airmixtures it is due to excited $\mathrm{CH}$ radicals. By varying equivalence ratio $(\varphi=$ 0.9 to 1.4) and for each grid, we find that the maximum temperatures in the flame can reach the adiabatic temperature in the area stoichiometric $(\varphi=1)$ and the highest intensity of turbulence (P grid), then it decreases by increasing equivalence ratio and reducing turbulence. Figures 9 further show that whiles the flame moves closer to the surface when subjected to increasing turbulence intensities. For further scrutinize the possible sensitivity of the flame structure to turbulence intensities, the profile of temperature in the flame coordinates are compared. Recognizing that profile comparison provides an even more stringent test of sensitivity than profile comparison, the results clearly show the existence of such sensitivity. For the same station and the same equivalence ratio, we see that turbulence intensity increase the temperature.

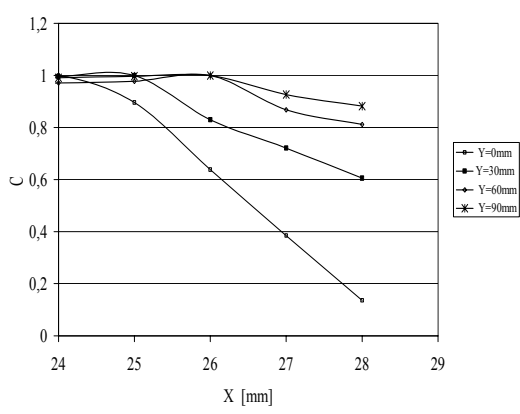

Figure 9: The field of mean variable in the flame brush.

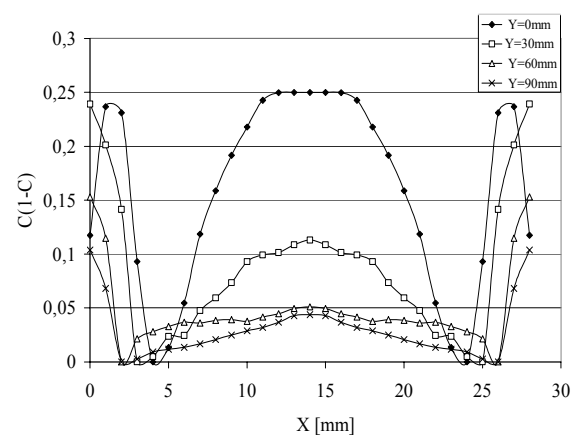

Figure 10: Fields of progress variable variance $\mathrm{C}^{2}=\mathrm{C}(1-\mathrm{C})$.

The mean progress variable is defined as follow: $C=\left(T-T_{u}\right) /\left(T_{b}-T_{u}\right)$, where $T_{b}$ is the adiabatic flame temperature, and $\mathrm{T}_{\mathrm{u}}=298 \mathrm{~K}$. The evolution of the progress variable along the axis of $\mathrm{V}$-shape flame is shown in figure 9. The results of variable progress $\langle\mathrm{C}>$ can be extracted from the temperature fields. The increase of the mean progress variable, $<\mathrm{C}>$ along the axial direction is consistent with the flame temperature, and they increase monotonically with X. The scalar profiles of figure 9 are typical of wrinkled flames found in other flame configuration such as stagnation flow stabilized flames, $\mathrm{V}$ flames and large conical flames (Cheng et al. [4]). The main differences are the flame zone thickness. The profiles are not perfectly symmetrical this is probably an imperfection of the burner. The curves of $\left\langle\mathrm{C}^{1^{2}}\right\rangle$ (figure10) can then be deduced 
from the ones of $\langle\mathrm{C}>$. These results are interest for comparisons with prediction methods. They will also be directly useful for further discussions though comparisons with other quantities.

\section{Conclusion}

From the temperature fields, the flame heights were determined. The latter allows one to show the existence of three zones: an area of lean flame characterized by important heights of flame and a weak wrinkling. A second zone corresponds to the localization of the stoichiometric line with a significant reduction in the height of the flame and an increase in wrinkling. The last zone of high equivalence ratio is where an increase in the size of the flames and a reduction in_wrinkling are noticed. One observes a shift of these minimal sizes towards the interior as a function of the turbulence intensity increase. The overall reaction is exothermic combustion, acceleration are usually corresponds to an increase in temperature in the reaction zone. More precisely this reaction induced considerable heat release in a very thin zone leading to very high temperature gradients. The equivalence ratio plays a very important role in terms of the quantity of heat release, its variation affects different parameters. Turbulence raises the temperature, so the turbulence improves combustion. The compensation digital improves the measurement results.

\section{References}

[1] Boulahlib M.S., Renou B., Boukhalfa A. and Nemouchi, Z., "Caractérisation expérimentale de la structure dynamique et scalaire d'une flamme turbulente de prémélange $\mathrm{CH}_{4}$-air: par PIV et tomographie Laser, Sciences \& Technologie $\mathrm{N}^{\circ} 22 \mathrm{~B}$, pp 67 78, décembre 2004.

[2] Bradly D. and Matthews K. J., "Measurement of high gas temperatures with wire thermocouple", Mechanical Engineering Science, Vol. 10 (4), 1968.

[3] Chan C.K., Wang H.Y. and Tang H.Y "Effect of intense turbulence on turbulent premixed V-flame" International Journal of Engineering Science, 41 pp. 903 916, 2003.

[4] Cheng R.K., L. Talbot and Robben F., "Conditional velocity statistics in premixed $\mathrm{CH}_{4}$-air and $\mathrm{C} 2 \mathrm{H} 4$-air Turbulent Flames" $20^{\text {th }}$ Symposium (international) on Combustion, The Combustion Institute, pp. 453 461, 1984.

[5] Knaus D.A., Sattler S.S., and Gouldin F.C., "Three-dimensional temperature gradients in premixed turbulent flamelets via crossed-planed Rayleigh imaging" Combustion and Flame" 141: pp. 253 270, 2005.

[6] Larass N., "Caractérisation expérimentale des champs thermiques et dynamiques de la combustion dans une chaudière domestique modèle", Thèse de Doctorat, Université de Rouen, 2000.

[7] Miles P.C. and Gouldin F.C., "Mean reaction rates and flamelet statistics for reaction rate modeling in premixed turbulent flames" $24^{\text {th }}$ Symposium 
(international) on Combustion, The Combustion Institute, pp. 477 484, 1992.

[8] Neveu F., Corbin F., Perrin M. and Trinité M., "Simultaneous velocity and temperature measurements in turbulent flames", $7^{\text {th }}$ International Symposium on Applications of Laser Techniques to Fluid Mechanics, Lisbon Portugal, 1994.

[9] Nina M. and Pita G., "Measurements of fluctuating gas temperatures thermocouples", AGRAD conference proceedings, panel symposium, Bergen, Norway, pp. 32.1 10, 1985.

[10] Paranthoen P., Lecordier J.C. "Mesures de température dans les écouements turbulents", Revue Générale de Thermique pp. N²13, pp. 283 308, 1996.

[11] Peters N., "Laminar flamelet concepts in turbulent combustion $7^{\text {th }}$ Symposium (International) on Combustion, The Combustion Institute, pp. 461 468, 1986.

[12] Poinsot T., Veynante D., \& Candel S. "Quenching processes and premixed turbulent combustion diagrams", J. Fluid Mech., vol: 228, pp.561-606, 1991

[13] Poireaut B., "Mécanisme de combustion dans un brûleur méthane air de type 'swirl' Influence de l'intensité de la rotation", Thèse de Doctorat, Université de Poitiers France, 1997.

[14] Scadron M. D. and Warshawsky I, "Experimental determination of the time constant and Nussell numbers for bare-wire thermocouples ", National Advisory Committee for Aeronautics, Technical note 2599 Washington, 1952.

[15] Tang B.H.Y., and Chan C.K., "Simulation of flame surface density and burning rate of a premixed turbulent flame using contour advection" Combustion and Flame" 147, pp. 49 66, 2006. 